\title{
Numerical investigations of the influence of operational parameters on diffusion and migration in electrodialytic nitrate removal.
}

Fernando F. Rivera' ${ }^{1}$ Eligio P. Rivero ${ }^{2}$, Federico Castañeda-Záldivar ${ }^{3}, *$

Author contributions: F.F. Rivera, E.P. Rivero, and F. Castañeda contributed equally to the conceptualization and manuscript writing.

1 CONACYT-Centro de Investigación y Desarrollo Tecnológico en Electroquímica. Parque Tecnológico Querétaro s/n Sanfandila, Pedro Escobedo, Querétaro, México. C.P. 76703.

2 Departamento de Ingeniería y Tecnología, Universidad Nacional Autónoma de México, Facultad de Estudios Superiores Cuautitlán, Av. Primero de Mayo, Cuautitlán Izcalli, Estado de México, México. C.P. 54740.

3 Centro de Investigación y Desarrollo Tecnológico en Electroquímica. Parque Tecnológico Querétaro s/n Sanfandila, Pedro Escobedo, Querétaro, México. C.P. 76703. 
Appendix A1. Meshing study

In order to capture the drastic concentration and potential changes in the electrolyte next to the membranes, special attention was paid to $n_{x}$ variable, so the mesh study is focused on this variable. Other variables have little or no effects (for example $n_{m x}$ ) on the numerical results.

Table S1 shows the effect of the number of mesh elements on the x component of the flux of $\mathrm{NO}_{3}{ }^{-}$ions. The percent of deviation is defined as follows

$\frac{N_{i, x}-N_{i, x, \propto}}{N_{i, x, \propto}} \times 100$

Where $N_{i, x}$ is the x component of nitrate flux at the corresponding number of mesh elements and $N_{i, x, \propto}$ is the x component of nitrate flux at 45600 mesh elements.

Also, three points in the simulation domain were selected to verify changes in the numerical results of concentration and potential as the mesh was refined. The results calculated are shown in Table S2 where minor numerical variations were observed at the indicated coordinates.

Fig. S1 depicts de deviation percent vs. the number of mesh elements. The flux converges to $2.193 \times 10^{-3} \mathrm{~mol} \mathrm{~m}^{-2} \mathrm{~s}^{-1}$.

Fig. S2 shows the mesh used in calculations

Table S1. Deviation of x-component of nitrate flux as a function of mesh elements

\begin{tabular}{|l|l|l|l|l|l|l|}
\hline \multicolumn{4}{|l|}{ Number of mesh elements } & Flux x NO${ }^{-}$ & Deviation \\
\hline Total & $n_{y}$ & $n_{x}$ & $r_{x}$ & $n_{m x}$ & mol m$^{-2} \mathrm{~s}^{-1}$ & $\%$ \\
\hline 6600 & 100 & 20 & 10 & 3 & 0.0021959 & 0.12767316 \\
\hline 9600 & 100 & 30 & 10 & 3 & 0.0021943 & 0.05471707 \\
\hline 12600 & 100 & 40 & 10 & 3 & 0.0021937 & 0.02735853 \\
\hline 15600 & 100 & 50 & 10 & 3 & 0.0021933 & 0.00911951 \\
\hline 18600 & 100 & 60 & 10 & 3 & 0.0021933 & 0.00911951 \\
\hline 24600 & 100 & 80 & 10 & 3 & 0.0021932 & 0.00455976 \\
\hline 30600 & 100 & 100 & 10 & 3 & 0.0021931 & 0 \\
\hline 37200 & 100 & 120 & 10 & 3 & 0.0021931 & 0 \\
\hline 45600 & 100 & 150 & 10 & 3 & 0.0021931 & 0 \\
\hline
\end{tabular}

Table S2. Variation of concentration and potential in three selected domain points

\begin{tabular}{|l|l|l|l|l|l|l|}
\hline \multirow{2}{*}{$\begin{array}{l}\text { Num mesh } \\
\text { elements }\end{array}$} & \multicolumn{3}{|l|}{ Concentration/ $\mathrm{mol} \mathrm{m}^{-3}(x, y$ coordinates $)$} & \multicolumn{3}{l|}{ Potential/ V $(x, y$ coordinates $)$} \\
\cline { 2 - 7 } & $(0.00165,0.09)$ & $(0.00315,0.09)$ & $(0.00165,0.02)$ & $(0.00165,0.09)$ & $(0.00315,0.09)$ & $(0.00165,0.02)$ \\
\hline 6600 & 387.78 & 421.29 & 441.66 & 0.24466 & 0.29906 & 0.24484 \\
\hline 9600 & 387.86 & 421.35 & 441.7 & 0.24471 & 0.29908 & 0.24485 \\
\hline 12600 & 387.9 & 421.38 & 441.71 & 0.24473 & 0.29909 & 0.24486 \\
\hline
\end{tabular}




\begin{tabular}{|l|l|l|l|l|l|l|}
\hline 15600 & 387.94 & 421.41 & 441.73 & 0.24474 & 0.2991 & 0.24487 \\
\hline 18600 & 387.92 & 421.39 & 441.72 & 0.24474 & 0.2991 & 0.24487 \\
\hline
\end{tabular}

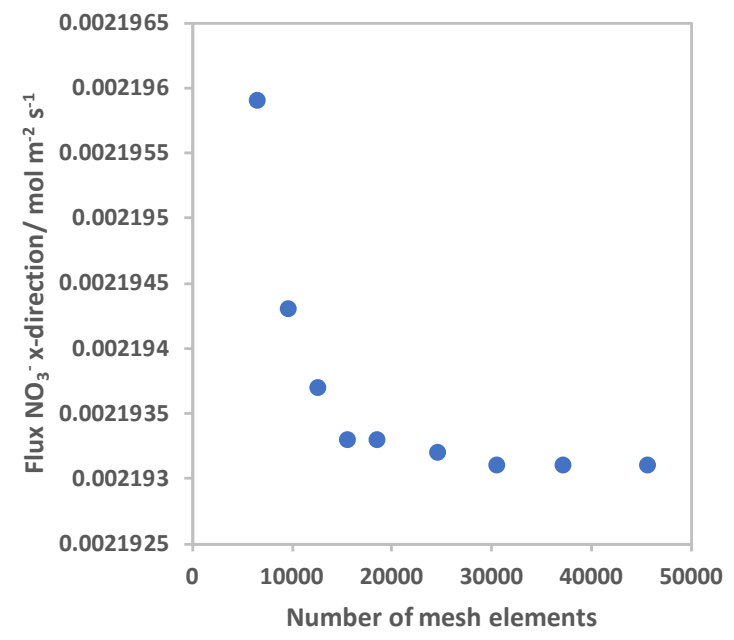

Fig. S1. Effect of number of mesh element on nitrate flux

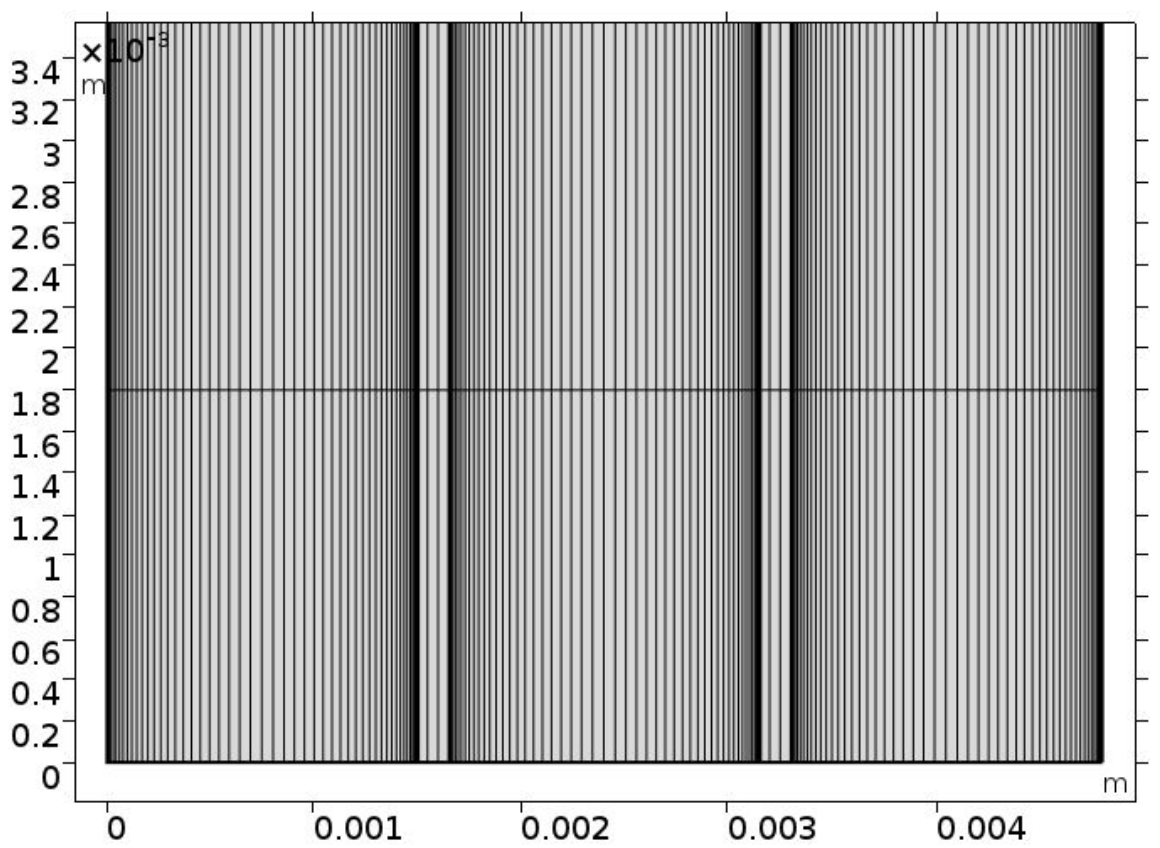

Fig. S2. The meshing of the inferior zone of the ED cell used in the simulation 
Appendix A2. Limiting current determination on membranes.

a)

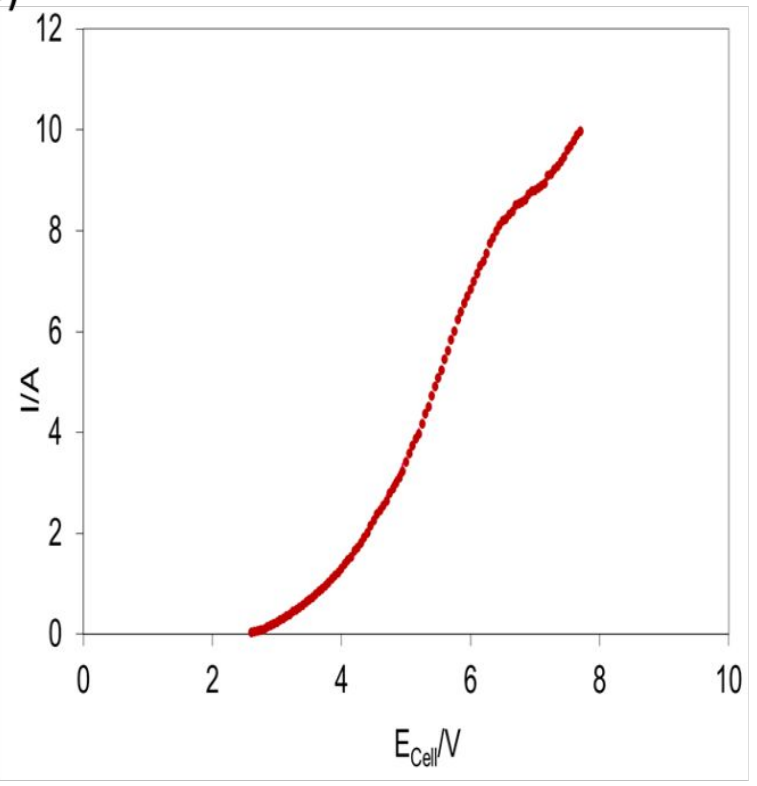

b)

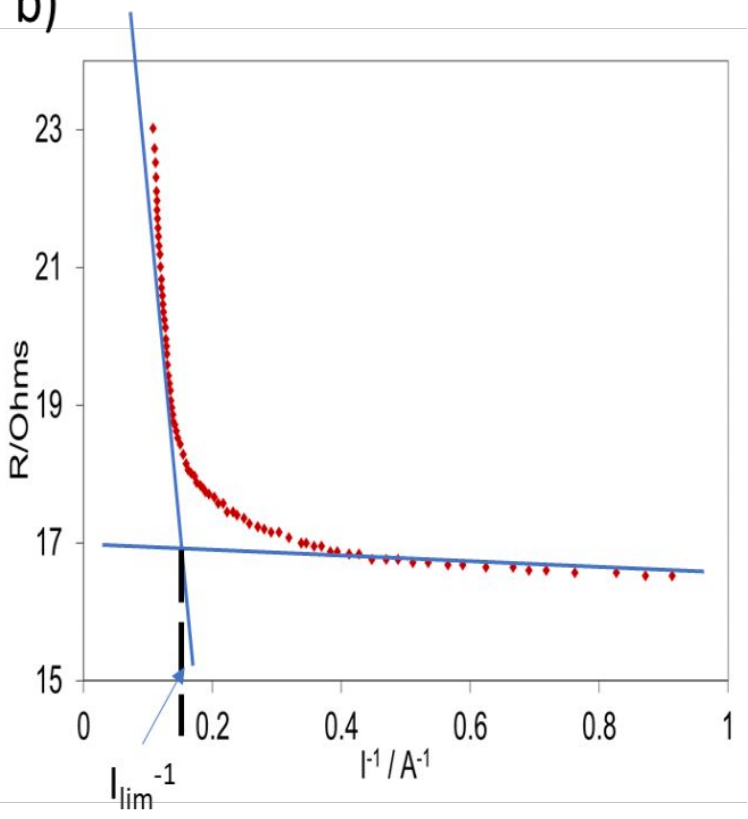

Figure S3. Determination of limiting current in CMV-AMV membrane pairs, by resistance method. a) Polarization Curves; b) Total resistance vs reciprocal of total current. 
Appendix 3. Additional calculations.
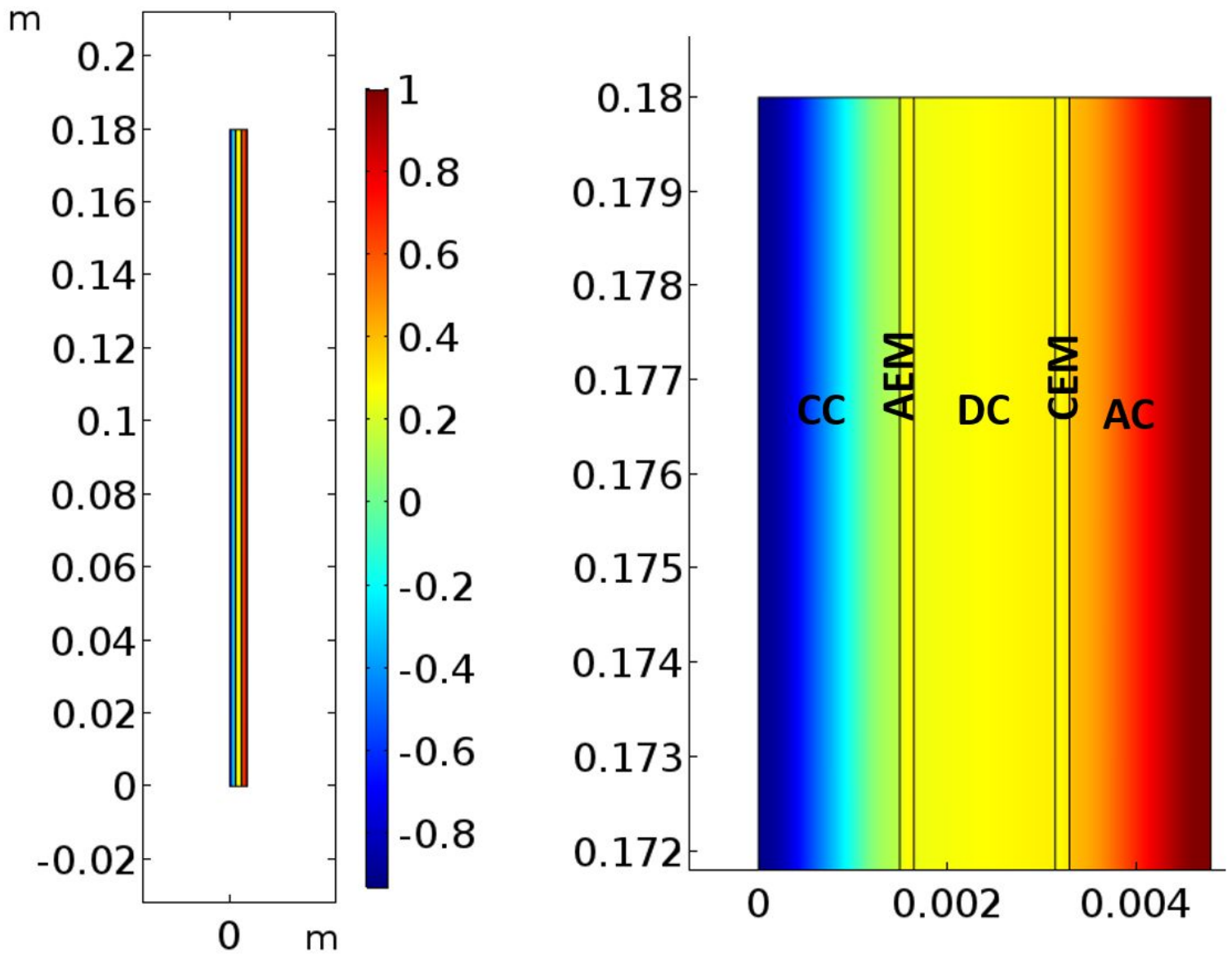

Figure S4. Calculation of potential distribution along X-coordinate on the electrodialysis unit at a flow rate of $25 \mathrm{dm}^{3} \mathrm{~min}^{-1}$ considering an applied current of $3.59 \mathrm{~A}$. The electrolyte potential distribution appears to be uniform along the $\mathrm{x}$-coordinate, this behavior is typical for a parallel plate electrochemical cell configuration. The values of electrolyte potential are from -0.9 for the cathodic compartment to $1.1 \mathrm{~V}$ at the anodic compartment. Within the cathodic and anodic compartment, an important variation of electrolyte potential is observed, meanwhile in the central compartment a constant value of such potential was calculated. This indicates that ohmic drop through the cell is more prominent in cathodic and anodic 
compartments than in the central compartment. This is likely because the strong concentration gradients of ionic species could increment the ohmic drop at the different electrolytic compartments, where a greater concentration of ionic species is present. 


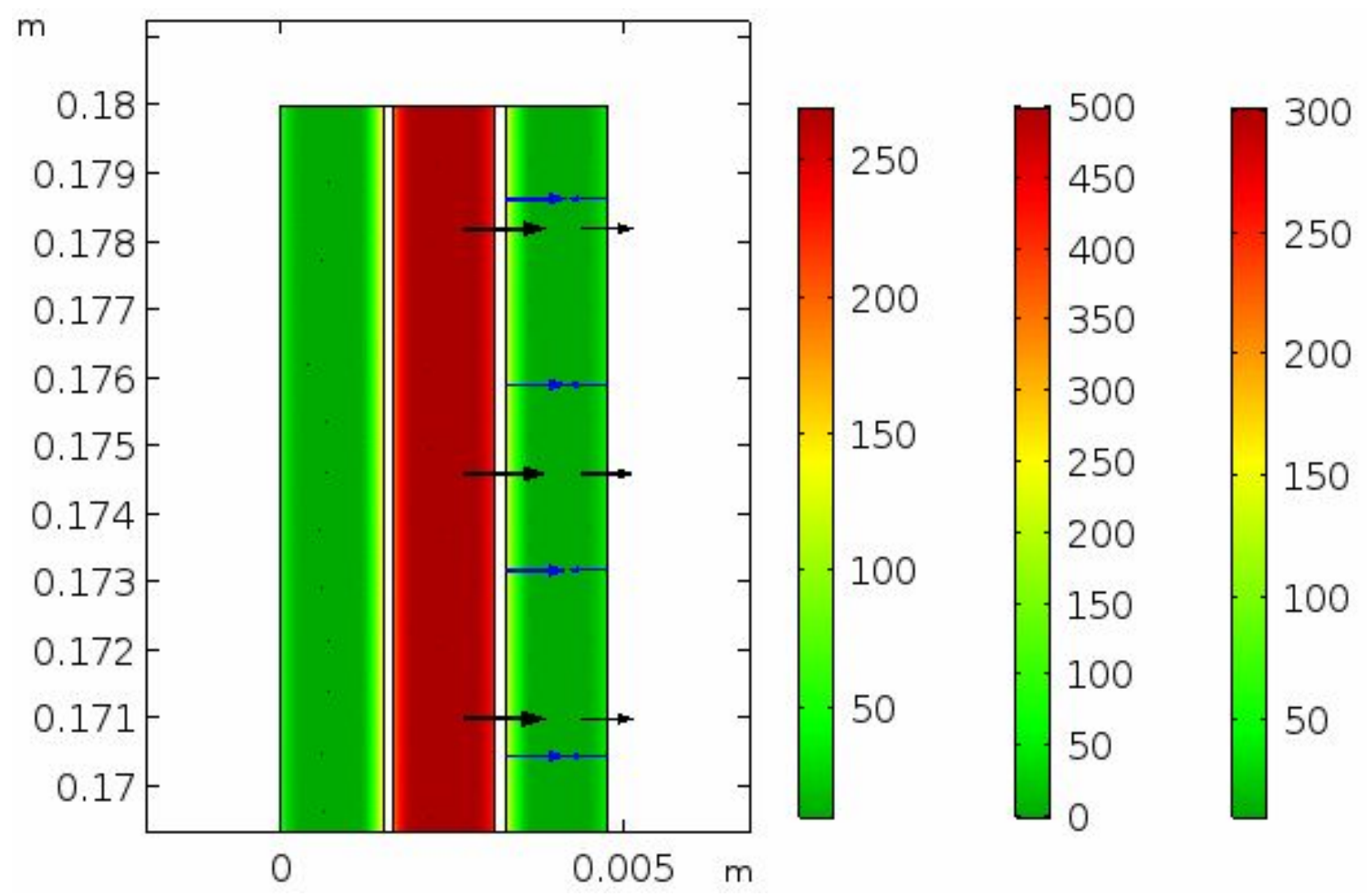

Figure S5. Concentration calculated slide at $25 \mathrm{LPH}$ and $\mathrm{t}=60 \mathrm{~min}$. 